\title{
PEPTIDE MODULATORS OF RAC1/TIAM1 PROTEIN-PROTEIN INTERACTION: AN ALTERNATIVE APPROACH FOR CARDIOVASCULAR DISEASES
}

\author{
Alessandro Contini ${ }^{1}$, Nicola Ferri ${ }^{2}$, Raffaella Bucci ${ }^{1}$, Maria Giovanna Lupo ${ }^{2}$, Emanuela Erba $^{1}$, \\ Maria Luisa Gelmi ${ }^{1}$, Sara Pellegrino ${ }^{1 *}$ \\ ${ }^{1}$ University of Milano, Department of Pharmaceutical Sciences, Milano, Italy \\ ${ }^{2}$ University of Padova, Department of Pharmaceutical and Pharmacological Sciences, Padua, Italy \\ * corresponding author \\ e-mail: sara.pellegrino@unimi.it
}

\section{ABSTRACT}

Rac1 GTPase interaction with guanine nucleotide exchange factor Tiam1 is involved in several cancer types and cardiovascular diseases. Although small molecules interfering with their protein-protein interaction (PPI) were identified and studied, the ability of small peptides and peptide mimics acting as Rac1/Tiam1 PPI inhibitors has not been yet explored. Using computational alanine scanning (CAS), the "hot" interfacial residues have been determined allowing the design of a small library of putative PPI inhibitors. In particular, the insertion of an unnatural alpha, alpha disubstituted amino acid, $i$. e. norbornane amino acid, and the side chain stapling have been evaluated regarding both conformational stability and biological activity. REMD calculations and CD studies have indicated that one single norbornane amino acid at the N-terminus is not sufficient to stabilize the helix structure, while the side-chain stapling is a more efficient strategy. Furthermore, both engineered peptides have been found able to reduce Rac1-GTP levels in cultured human smooth muscle cells, while wild type sequence is not active.

\section{INTRODUCTION}

The protein Racl is an ubiquitous Rho GTPase, i. e. a small monomeric protein that bounds GTP, which is involved in several cancer types and cardiovascular diseases. ${ }^{1,2}$ For instance, Rac1 regulates cellular events associated to atherogenesis, such as smooth muscle cell (SMC) migration ${ }^{3}$ and proliferation, ${ }^{4}$ membrane trafficking and leukocyte-endothelial cell interaction. ${ }^{5}$ Its activity depends on the equilibrium between inactive GDP-bound and active GTP-bound form, a cycling regulated by the guanine nucleotide exchange factors (GEFs) as activators, and the GTPase activating proteins (GAPs) and GDP dissociation inhibitors (GDIs) as negative regulators. The T-cell lymphoma invasion and metastasis 1 (Tiam1) protein is a specific GEF for Rac1 and is crucial for cell-cell 
adhesion and cell migration. Tiam-1 has also shown to play a pivotal role in cardiac hypertrophy associated to heart failure. ${ }^{6}$

The pharmacological inhibition of Rac1 has been first based on the interference with the prenylation process by using either the HMG-CoA reductase inhibitors, statins, or the prenyl transferase inhibitors, such as the geranylgeranyl transferase inhibitor GGTI-2418 $8^{7}$ However, both approaches certainly were able to affect the function of Rac1, but not in a selective manner thus inhibiting all the intracellular prenylated proteins. An important breakthrough in the development of selective Rac1 inhibitors has been observed with the identification of the compound NSC23766. ${ }^{8}$ This small molecule fits into the surface groove of Rac1 involved in the binding with GEFs, thus interfering with the Tiam1-Rac1 interaction in a selective manner, without interfering with other small $\mathrm{G}$ proteins, such as Cdc-42 and RhoA. From this pioneer observation, additional and more potent selective Rac1 inhibitors have been identified. ${ }^{8-12}$ A second approach to selectively interfere with the cellular function of small $\mathrm{G}$ proteins is represented by the identification of compounds capable to interfere with the PPI between the small G protein and their effectors. ZINC69391 is able to interfere with the interaction of Rac1 with Dock180, a Rac1 activator in glioma invasion ${ }^{13}$. 1A-116 modulates Rac1-PRex1 interaction ${ }^{14}$. Phox-I1 targets the interactive site of p67phox with Rac1 GTPase with a submicromolar affinity and very efficiently inhibits the ROS production in neutrophils at $20 \mu \mathrm{M}$ concentration. ${ }^{15}$ EHT-1864 is another example of Rac1 inhibitor that binds Rac1 with high affinity compared to GDP/GTP, retaining Rac1 in an inert and inactive state ${ }^{16}$. Finally, Fasudil, the inhibitor of the Rho-kinase, a pivotal effector of the small $\mathrm{G}$ protein RhoA, has been developed and registered in Japan for the treatment of cerebral vasospasm after surgery in subarachnoid hemorrhagic patients. ${ }^{17}$ Although small molecules dominated the drug industry in the last century, a raising interest has been observed in the recent years toward peptide drugs. ${ }^{18,19}$ Indeed, peptides can help to overcome some of the main questions that make a small molecule candidate fail during the latest phases of the drug development pipeline, in particular toxicity and tolerability. ${ }^{19}$ Conversely, peptides are considered rather safe and well tolerated, and their metabolic course is easily predictable. Furthermore, libraries of peptides can be easily synthetized, starting by readily available and generally non-expensive building blocks represented by both natural and non-natural amino acids. Moreover, when targeting PPIs, peptides represent the "natural" PPI interface partners, and an active peptide can thus be considered an excellent starting point for future development of bioactive compounds..$^{20,21,22,23}$ On the other hand, a common drawback of natural peptides is that they often show a low metabolic stability. Furthermore, the high conformational freedom of small peptides might play against potency, since the reduction of entropy upon association with the target protein reflects on a higher binding free 
energy. ${ }^{24}$ However, the use of non-natural amino acids or simple chemical modifications to the peptide structure can help in overcoming these disadvantages. ${ }^{25}$

For the above reasons, we were interested in providing an alternative to the already available small molecules, which might be used as a lead to develop new potent, selective and safe compounds acting as inhibitors of the Rac1-Tiam1 PPI. Starting from a helical peptide segment derived from the sequence of Tiam1 that interacts with Rac1, we designed a small peptide library. In particular, the insertion of an unnatural alpha, alpha disubstituted amino acid, i.e. norbornane amino acid, ${ }^{26}$ and the side chain stapling $27,28,29$ have been evaluated as strategies to obtain engineered peptides. Indeed, these approaches might lead to peptides that are stable to metabolism, inherently stable to proteases and peptidases, and can fold into well-ordered secondary structures. ${ }^{30}$

\section{MATERIALS AND METHODS}

\section{Molecular modelling}

The starting geometry of the Tiam1-Rac1 complex was downloaded from the Protein Data Bank (PDB file 1FOE), ${ }^{31}$ GDP and the coordinated Mg ion were transferred into the Rac1 catalytic site from the crystal structure of GDP-bound Rac1 complexed with P21 (PDB file 1I4D). ${ }^{32}$ The "Structure Preparation" module of the MOE software ${ }^{33}$ was then used to cap the $\mathrm{N}$ - and C-terminus by acetyl and methylamino groups, to replace selenomethionine by methionine and to reconstruct residues with missing atoms. The system was then protonated at $\mathrm{pH}=7$ by using the "Protonate 3D" module of MOE. Then it was minimized up to a gradient of $0.1 \mathrm{kcal} \mathrm{mol}^{-1} \AA^{-1}$ using the AMBER10EHT force field and the Born solvation model, implemented in MOE, by keeping the backbone atoms constrained to the original position. The system was then loaded into the leap module of the AmberTools 16 package, ${ }^{34}$ and solvated by an octahedral box of TIP3P water molecules. ${ }^{35}$ Force field parameters were assigned based on the ff $99 S B$ force field, ${ }^{36}$ while GDP parameters were obtained from the Amber Parameters Database. ${ }^{37}$ The system was then equilibrated by multiple steps of minimizations, NVT and NPT equilibrations, as reported in previous works. ${ }^{38-40} \mathrm{~A}$ NPT production run of 12 ns was conducted with the pmemd module of the Amber16 suite. ${ }^{34}$ The same protocol was adopted for the simulation of complexes between Rac1 and designed peptides. The trajectories were analyzed by using the cpptraj module of AmberTools 16 .

Molecular Mechanics Generalized Born (MM-GBSA) calculations and computational alanine scan (CAS) analyses were performed on the last $4 \mathrm{~ns}$ of production trajectories by using the MMPBSA.py script included in the AmberTools suite. ${ }^{41}$ The OBC(II) solvent model with a saline concentration of $0.15 \mathrm{M}$ was requested. ${ }^{42}$ Calculations were performed on 100 evenly spaced snapshots extracted from the solvated trajectory and the entropy contribution was neglected. 
Replica exchange molecular dynamics (REMD) simulations ${ }^{43}$ on designed peptides were performed by adapting previously reported protocols. ${ }^{44-51}$ The combination of the ff99SB force field and the OBC(II) model was requested, and 20 replica were run for $100 \mathrm{~ns}$ at temperatures spanning from 270.0 to $654.5 \mathrm{~K}$ (see Table S1, Supporting Information for details). Parameters for non-natural amino acids were derived as described previously. ${ }^{44,45}$ Analyses were performed with cpptraj on the REMD trajectory reconstructed at $296.7 \mathrm{~K}$. Cluster analyses were done by using the average-linkage algorithm sampling one every two frames. A total of five cluster were requested and the pairwise mass-weighted Root Mean Squared Displacement (RMSD) was used as a metric. The analysis was performed periodically and the simulation was considered converged when the difference in population for the principal cluster between two consecutive blocks of 25 ns was below $10 \%$.

\section{Peptide synthesis}

Fmoc Rinkamide resin, Fmoc-protected amino acids, HBTU, HOBT and DIEA were purchased from Iris Biotech Gmbh (Germany). Solvents, piperidine and other reagents were purchased from SigmaAldrich (Germany). All peptides were synthesized using a CEM Liberty peptide synthesizer and purified using RP-HPLC with a Jasco BS-997-01 instrument and a DENALI C-18 column from GRACE VYDAC $(10 \mu \mathrm{m}, 250 \times 22 \mathrm{~mm})$. ESI mass spectra were recorded on a LCQ Advantage spectrometer from Thermo Finnigan.

Linear peptides synthesis. Linear peptides were prepared by Fmoc based microwave assisted solid phase synthesis. ${ }^{52}$ The peptides were assembled on Fmoc Rinkamide ( $0.4 \mathrm{meq} / \mathrm{g}$ substitution) using a 5-fold molar excess of Fmoc-protected amino acids dissolved (0.2 $\mathrm{M}$ in NMP) and HOBT/HBTU/DIEA (5:5:10) as coupling reagents. Coupling reactions were performed for 5 min at $40 \mathrm{~W}$ with a maximum temperature of $75^{\circ} \mathrm{C}$. Deprotection was done in two steps using $20 \%$ piperidine in DMF (5 min and 10 min each).

Coupling of Norbornane amino acid. (1R, 2R, 4R) $\mathrm{N}$-Ac-Nrb-OH ${ }^{26}$ (2 eq) dissolved in DMF was added to the $N$-deprotected peptide on resin. HOBt (2 eq) and DIC ( 2 eq) were added and the mixture was stirred for 12 hours (coupling repeated twice until negative Kaiser test).

$N$-Terminus acetylation. Synthesized peptides were $N$-terminus manually acetylated on resin using acetic anhydride (10 eq) and DIPEA (10 eq) in DCM for 30 min swelling at room temperature.

$N$-Terminus Fitc-conjugation. The labelling was performed on resin, before the cleavage, using 5(6)carboxyfluorescein (10 eq) and HOBT/DIC (10 eq) as coupling reagents. The coupling reaction was performed twice (1 hour each one) in the dark under vigorous shaking. $20 \%$ piperidine in DMF was then added and the mixture was shaken for 1 hour. 
Removal of Alloc-Orn and Allyl-Asp protecting groups. A solution of $\mathrm{PhSiH}_{3}$ (24 eq) in anhydrous DCM was added to the $\mathrm{N}$-acetylated peptide on resin. The mixture was stirred for 2 min under nitrogen. $\mathrm{Pd}\left(\mathrm{PPh}_{3}\right)_{4}(0.5$ eq in anhydrous $\mathrm{DCM})$ was added to the vessel and the reaction was left under stirring for $1.5 \mathrm{~h}$. The procedure was repeated twice. Finally, the resin was washed with DMF and DCM.

On resin side chain Asp-Orn cyclization. After Orn and Asp side chain deprotection, the resin was swelled in NMP. A solution of HOBt/HBTU (6 eq) in DMF was added to the reaction vessel. DIPEA (12 eq) was added. The reaction was left under stirring for $2 \mathrm{~h}$. The procedure was repeated until the Kaiser test was negative.

Cleavage from the resin. Cleavage was performed using $10 \mathrm{ml}$ of Reagent $\mathrm{K}$ (TFA/phenol/water/thioanisole/EDT; 82.5/5/5/5/2.5) for $180 \mathrm{~min}$. After cleavage, peptides were precipitated out and washed using ice-cold anhydrous ethyl ether. All peptides were purified by RPHPLC using a gradient elution of 5-70\% solvent B (solvent A: water/acetonitrile/TFA, 95/5/0.1; solvent B: water/acetonitrile/TFA, 5/95/0.1) over $20 \mathrm{~min}$ at a flow rate of $20 \mathrm{ml} / \mathrm{min}$. The purified peptides were freeze-dried and stored at $0^{\circ} \mathrm{C}$ and analysed using analytical HPLC ( $95 \%$ A for 5 min.; 95-30\% A over 20 minutes) and ESI mass spectrometry (see Supporting Information).

\section{Circular Dichroism}

Circular dichroism spectra were collected using a Jasco J-800 spectropolarimeter. The spectral scans were collected between 250 and $190 \mathrm{~nm}, 0.1 \mathrm{~nm}$ data pitch, at $50 \mathrm{~nm} / \mathrm{min}$ scanning speed. Each spectrum is the result of 3 averaged accumulations. $100 \mu \mathrm{M}$ peptide stock solutions were prepared in HPLC grade water and then diluted to $20 \mu \mathrm{M}$ final concentration with water or trifluoroethanol (TFE). The CD spectra were plotted as mean residue ellipticity $\theta\left(\right.$ degree $\left.\mathrm{x} \mathrm{cm}^{2} \mathrm{x} \mathrm{dmol}^{-1}\right)$ versus wavelength $\lambda(\mathrm{nm})$. Noise-reduction was obtained using a Fourier-transform filter program from Jasco.

Cell Culture and G-LISA assay.

Human SMCs (A617 from human femoral artery) were grown in monolayers at $37^{\circ} \mathrm{C}$ in a humidified atmosphere of $5 \% \mathrm{CO}_{2}$ in DMEM supplemented with $10 \%$ (v/v) FCS, $100 \mathrm{U} / \mathrm{mL}$ penicillin, 0.1 $\mathrm{mg} / \mathrm{mL}$ streptomycin, and nonessential amino acids. The medium was changed every third day. For the experiments cells were seeded at a density of $2 \times 10^{5} / 35 \mathrm{~mm}$ Petri dish and incubated with DMEM supplemented with $10 \%$ FCS; 24 h later the medium was changed to one containing $0.4 \%$ FCS, and the cultures were incubated for $48 \mathrm{~h}$. At this time, the peptides were added to the cultured medium, and after $4 \mathrm{~h}$ the intracellular amounts of Rac1-GTP were determined by using the G-LISA assay, as previously described ${ }^{12}$ 
Cellular uptake of the fluorescence-labeled peptide

After 72 hours incubation with increasing concentrations of peptide, the cells were trypsinized and centrifuged for $5 \mathrm{~min}$ at $1,000 \mathrm{rpm}$. Pellets were resuspended in $0.5 \mathrm{~mL}$ PBS and the fluorescence signal was recorded on the FL2 channel of a FACS scan flow cytometer (Becton Dickinson) and analyzed with ModFit LT software (Verity Software House, Topsham, ME, USA). The cellular uptake of the peptide was expressed as mean florescence index (MFI) of 10,000 cells per sample.

\section{Statistical analysis}

Data are expressed as mean $\pm \mathrm{SD}$. Student's t test was used to evaluate differences between groups, and statistical significance was assigned when $\mathrm{P}<0.05$.

\section{RESULTS AND DISCUSSION}

Design of engineered peptides. Tiam1 interacts with Rac1 through two helices, CR1 and CR3, and through the C-terminal portion of helix $\alpha 9$ (Fig 1A) of the DH domain (AAs 1034-1258). On the Rac1 side, interactions with Tiam1 are mediated by two loops, switch 1 (AAs 25-39) and switch 2 (AAs 57-75), and by non-conserved residues between switches, ensuring proper GEF/Rac1 pairing. ${ }^{31}$ The comparison between the Rac1-Tiam1 complex and the crystal structure of a Zn-stabilized Rac1GDP complex shows that the binding with Tiam1 alters the conformation of switches 1 and 2 thus reducing the affinity for $\mathrm{Mg}$ ion and favoring GDP-GTP exchange (Fig 1B). ${ }^{32}$

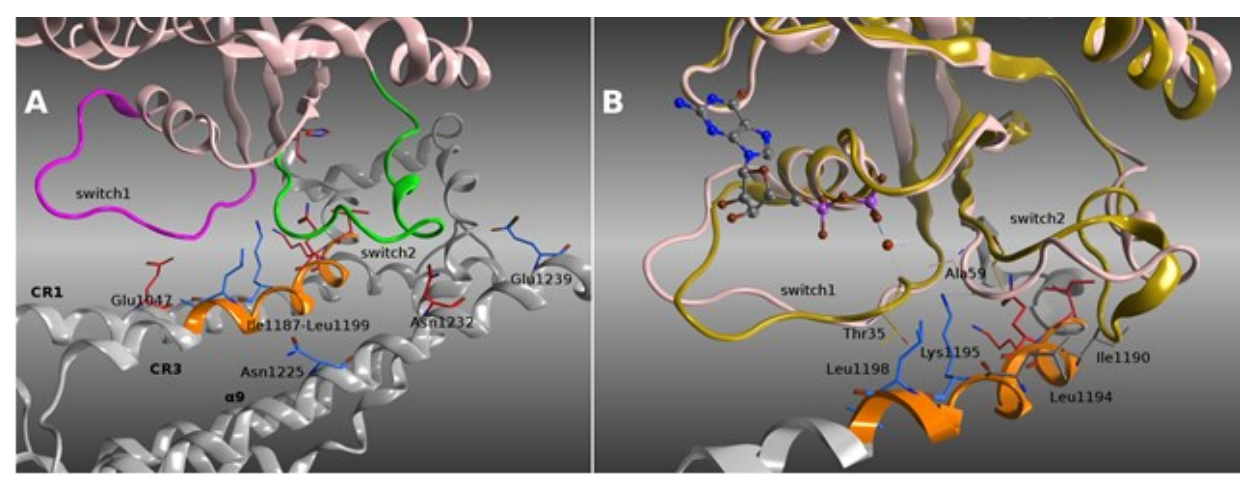

Figure 1. A) Crystal structure of Tiam1-Rac1. DH domain of Tiam1 and Rac1 are represented as grey and pink ribbons. Rac1 "switch 1" and "switch 2" are magenta and green, respectively. Tiam1 residues calculated as "hot-spots" and "warm-spots" are red and cyan, respectively. In orange is represented the Tiam1 sequence containing the largest number of consecutive hot and warm spots 
(AAs 1187-1199 of CR3 helix). B) Superposition of crystal structures of Tiam1-bound (pink) and GDP-bound (tan) Rac1 complexes.

Interactions with switch 1 are mediated by CR1, while interactions with $\alpha 9$ helix seem to be responsible of the altered conformation of switch 2. The CR3 helix of Tiam1 is sandwiched between switches 1 and 2 and interacts with the flanking regions of both loops and with residues between them, including W56 which is important in the binding with small molecule inhibitors. ${ }^{8}$

Starting from the Rac1-Tiam1 crystal structure, we performed MD simulations followed by computational alanine scanning (CAS) analyses using the molecular mechanics generalized Born (MM-GBSA) approach. CAS allows evaluating the variation in binding free energy $\left(\Delta \Delta G_{\mathrm{b}}\right)$ following the mutation to Ala of selected interfacial residue. A total of 52 Tiam residues lying at the contact interface with Rac1 (from Leu1035 to Glu1240; see Table S2, Supporting Information for the full list of residues and computed $\Delta \Delta G_{\mathrm{b}}$ ) were evaluated in the CAS analysis. Interfacial AAs were classified as hot-spots when the computed $\Delta \Delta G_{\mathrm{b}}$ was $>4 \mathrm{kcal} / \mathrm{mol}$, warm-spots where $2<\Delta \Delta G_{\mathrm{b}}<4 \mathrm{kcal} / \mathrm{mol}$ and cold-spots where $\Delta \Delta G_{\mathrm{b}}<2 \mathrm{kcal} / \mathrm{mol}$ (Table 1 and Fig.1A).

Table 1. Hot- and warm-spots from CAS analysis of CR3 helix of Tiam1 complexed with Rac1. Free Energy Differences in Binding Energy $\left(\Delta \Delta G_{b}\right)$ upon Mutation of the Selected Residues to Alanine are Reported in $\mathrm{kcal} / \mathrm{mol}$.

\begin{tabular}{lc}
\hline Residue & \multicolumn{4}{c}{$\boldsymbol{G} \boldsymbol{b}$} \\
\hline I1187 & 4.5 \\
K1188 & 7.5 \\
Q1191 & 7.9 \\
L1194 & 4.1 \\
K1195 & 3.8 \\
L1198 & 2.4 \\
L1199 & 2.8 \\
\hline
\end{tabular}

Energy values reported in Table 1 fit well with the qualitative analysis of Worthylake et al. ${ }^{31}$ and confirm that the Rac1-Tiam1 interaction is principally exerted by a 13 residue long helix belonging to CR3 (hereafter referred as I1 187-L1199 and colored in orange in Fig.1). Since I1187-L1199 seems 
to mediate Tiam1-Rac1 interaction, but not the conformational change leading to GDP-GTP exchange, we took it as the starting point for the design of inhibitor peptides. (1-5) (2-6)

Two wild type (WT) peptides of 9 and 13 amino acids, WT9 and WT13 (Table 2), with acetyl and methylamino caps at the $\mathrm{N}$ and C-termini, were designed in complex with Rac1 and subjected to 12 ns of MD simulation. The former peptide contains all residues comprised by the hot-spots I1 187 and K1195, while the second also includes the two warm-spots L1198 and L1199. The geometry of both peptides corresponds to that found in the crystal structure. ${ }^{31}$ The binding energy was then calculated by MM-GBSA on the last $4 \mathrm{~ns}$ of the trajectory and resulted in $-31.5 \pm 5.7 \mathrm{kcal} / \mathrm{mol}$ and $-41.0 \pm 5.5$ $\mathrm{kcal} / \mathrm{mol}$ for WT9 and WT13, respectively (Table 2). Since WT13 scored a lower binding energy and a lower standard deviation, suggesting that it is able to better stabilize the complex with Rac1, it was selected as the starting point for the design of modified peptide. First, considering that the CR3 sequence interacting with Rac1 is helical, we evaluated the conformational preferences of WT13, since its excision from Tiam 1 could hardly allow the maintainment of its native helical conformation. Indeed, REMD simulations, followed by cluster analysis, showed that only the central portion of the peptide maintained a helical secondary structure, while the first two residues at the $\mathrm{N}$-terminus and the last four at the C-terminus, were disordered (Fig. 2A). Aiming to stabilize the helical conformation, without affecting the binding capabilities of the peptide to Rac1, we evaluated the mutation of the N-terminal I1 187 to the non-natural amino acid NRB (Fig. 2B), which in previous theoretical works showed a discrete capability of stabilizing $\alpha$-helices ${ }^{46}$ and a good propensity in inducing a right-handed helix screw sense. ${ }^{47}$ Among other non-natural amino acids, NRB was also chosen as a mimetic of aliphatic apolar amino acids. However, REMD simulation of the mutated peptide M1 did not provide the expected results, since the $\alpha$-helix was only marginally stabilized (Fig. 2B). On the other hand, MM-GBSA calculations conducted on the Rac1/M1 complex showed an improved binding energy (Table 2). 

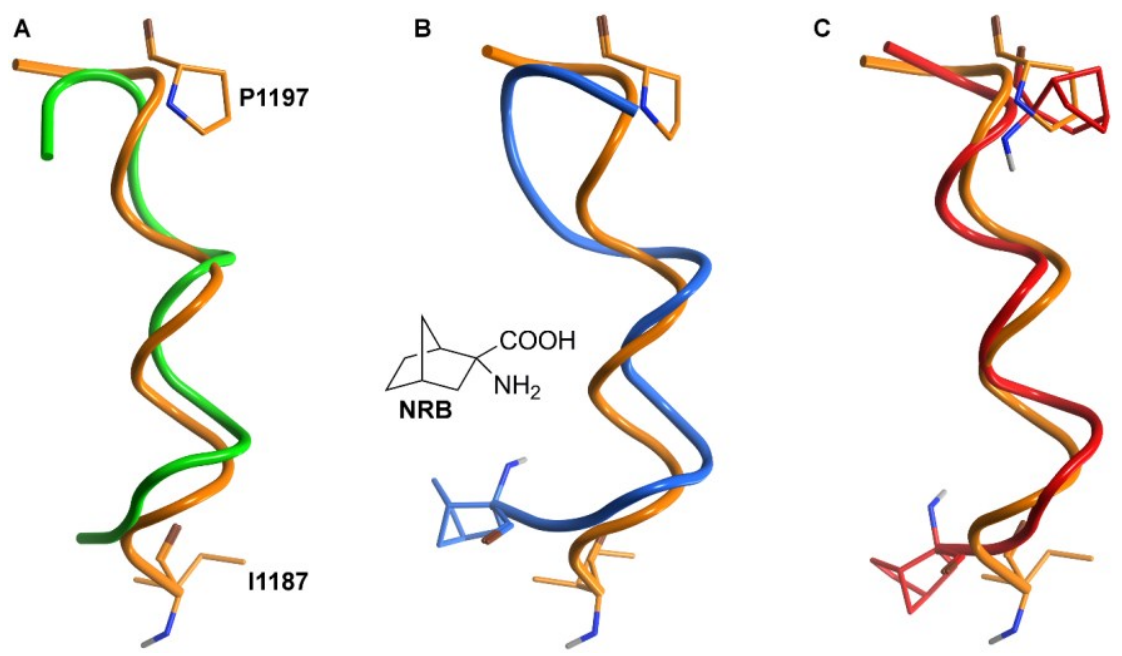

Figure 2. Superimposition of the crystal geometry of WT13 segment (orange) with the most representative geometries of: A) WT13 peptide (green) B) M1 (blue) and C) M2 (red) obtained by REMD simulations and cluster analysis.

We decided to evaluate theoretically a second mutant peptide (M2) were both I1 187 and P1197 were replaced by NRB (Fig. 2C). In this case, REMD simulations and cluster analyses showed a significant improvement in the stabilization of the helical secondary structure. On the other hands, binding energies comparable to the WT13 peptide were obtained (Table 2).

Table 2. Binding energies ( $\mathrm{kcal} / \mathrm{mol})$ calculated by MM-GBSA for peptides WT9, WT13, M1 and M2

\begin{tabular}{|l|l|l|}
\hline Peptide & $\boldsymbol{E}_{\text {MM-GBSA }}$ & Sequence \\
\hline WT9 & $-31.5 \pm 5.7$ & Ac-IKPIQRVLK-CONH \\
\hline WT13 & $-41.0 \pm 5.5$ & Ac-IKPIQRVLKYPLL-CONH \\
\hline M1 & $-52.4 \pm 9.2$ & Ac-(Nrb)KPIQRVLKYPLL-CONH \\
\hline M2 & $-36.7 \pm 5.6$ & Ac-(Nrb)KPIQRVLKY(Nrb)LL-CONH \\
\hline
\end{tabular}

Unfortunately, the synthesis of M2 peptide resulted challenging due to the low reactivity of NRB amino acid on solid phase that hampered its obtainment in significant amount for characterization and biological tests. We thus decided to follow a different approach to stabilize the secondary structure of the peptide, i.e. stapling the sidechains of some residues not involved in the binding..$^{27,28}$ Following suggestions from CAS analysis, we mutated in silico, using the MOE software, the cold- 
spots R1192 and Y1196 to ornithine (Orn) and aspartate, respectively. This mutation provided complementary sidechains at the correct distance to form an amidic bond. The two side chains were then linked and the geometry was optimized with MOE (AMBER10EHT force field, Born solvation model. ${ }^{33} \mathrm{We}$ observed that no dramatic variation in the backbone conformation occurred (Fig. 3), so the stapled peptide ST was selected for synthesis and biological evaluation, together with WT13 and M1.



Figure 3. Sequence and minimized geometry of the stapled peptide ST.

Peptide synthesis

WT13 peptide sequence and the two engineered sequences containing $(1 R, 2 R, 4 R) \mathrm{N}$-acetyl norbornane (NRB) amino acid ${ }^{26}$ in position 1 (M1 peptide) and the stapling between position 6 and 10 (ST peptide) have been chemically synthesized on Rink amide resin using microwave assisted solid phase peptide synthesis ${ }^{52}$ (Table 3).

Table 3 Synthesized peptide sequences and overall yields

\begin{tabular}{|l|l|l|}
\hline Peptide & Sequence & Yield (\%) \\
\hline WT13 & Ac-IKPIQRVLKYPLL-CONH 2 & 40 \\
\hline Fitc-WT13 & Fitc-IKPIQRVLKYPLL-CONH & \\
\hline M1 & Ac-(Nrb)KPIQRVLKYPLL-CONH 2 & 30 \\
\hline ST & Ac-IKPIQ(Orn)VLKDPLL-CONH 2 \\
\hline
\end{tabular}

Coupling reactions were performed using a five fold excess of Fmoc-amino acids, using HOBT/HBTU as activators and DIPEA as the base. In the case of stapled peptide ST, Alloc and Allyl 
protecting group have been used for side chain protection of Ornithine 6 and Aspartic acid 10, respectively. After linear ST peptide synthesis, the side chain deprotection has been performed using $\mathrm{Pd}\left(\mathrm{Ph}_{3}\right)_{4}$ and $\mathrm{PhSiH}_{3} .{ }^{53}$ Cyclization has been done using HOBt/HBTU and DIPEA in NMP. In the case of M1 peptide, norbornane coupling has been performed manually using $N$-Ac-Nrb (2 eq), HOBT/DIC (2 eq) and a double coupling protocol (12 hours for each coupling). In order to perform cell internalization studies, fluo-labelled Fitc-WT13 peptide has been also prepared (Table 3).

Circular dichroism (CD)

The secondary structures of WT13, ST and M1 peptides have been studied using circular dichroism (CD). In water, WT13 peptide is present as a mixture of different conformations as indicated by the negative Cotton effect below $200 \mathrm{~nm}$ (Figure 4A). The addition of 50\% trifluoroethanol (TFE) leads to an increase of the WT13 helical content (positive band at $190 \mathrm{~nm}$ and two negative shoulders at 208 and $222 \mathrm{~nm}$ ). A similar trend is observed also for the stapled ST peptide (Figure 4B), although in $50 \%$ TFE the helical stabilization seems higher (more intense positive $\pi-\pi^{*}$ and negative $n-\pi *$ amide transition bands). M1 peptide shows, instead, completely different CD spectra (Figure 4C). In water, M1 spectrum is characterized by a negative Cotton effect at $190 \mathrm{~nm}$ and by a strong positive band at around $208 \mathrm{~nm}$, suggesting a major contribution of the turn secondary structure to the overall conformation of the peptide. The spectrum does not change by varying both the $\mathrm{pH}$ and the temperature (data not shown). The addition of $50 \%$ TFE leads to a decrease of the intensity of the n$\pi^{*}$ amide transition band, probably indicating the increase in other conformations. These data confirmed the REMD calculations that indicated that the presence of only one NRB residue at Nterminus is not enough to stabilize helix structure (see before). 

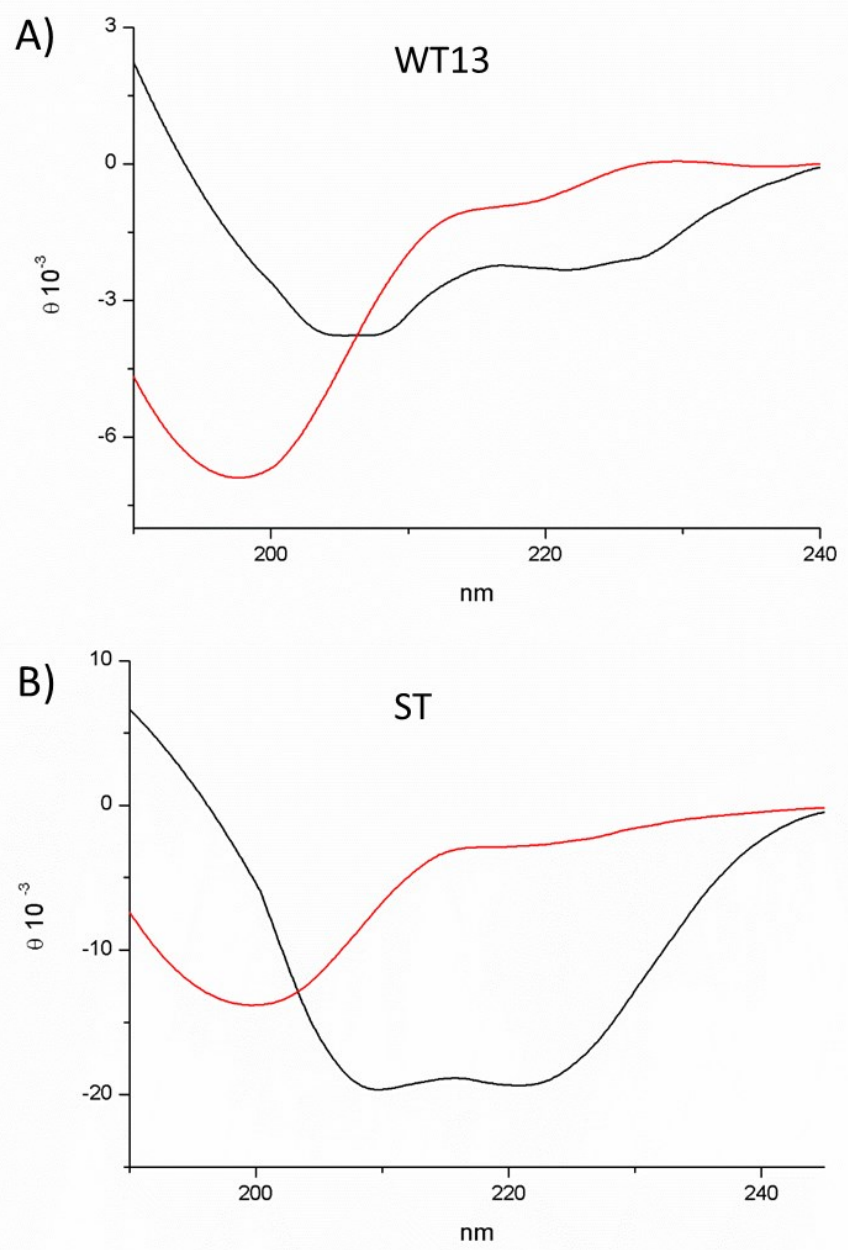


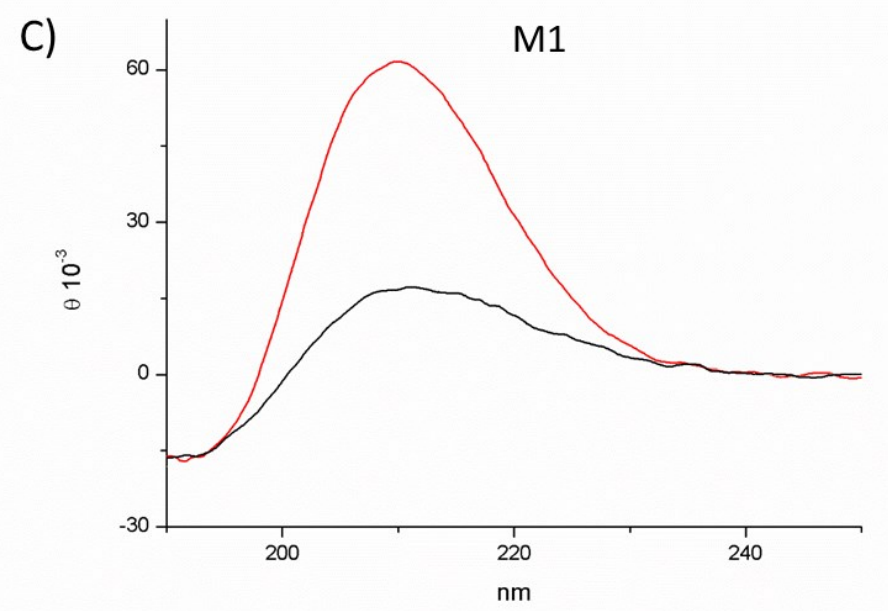

Figure 4. CD spectra in water (red line) and 50\% TFE (black line) of a) WT13, b) ST and c) M1 peptides

In order to investigate the pharmacological inhibition of Rac1 by the selected peptides, we first evaluated the capacity of WT13 to diffuse across the plasma membrane. By using labelled FitcWT13, we detected a nice concentration-dependent cellular uptake by flow-cytometry analysis, demonstrating the capability of this peptide to be uptake by the cells and potentially reaching its intracellular target (Figure 5).

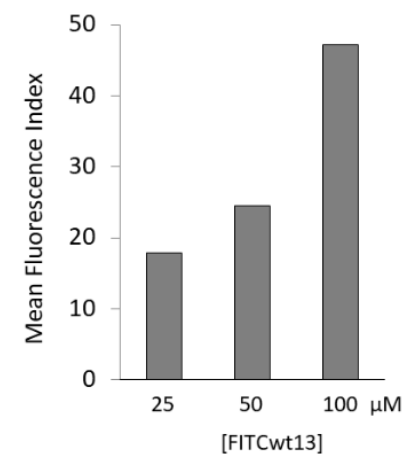

Figure 5. Cellular uptake of Fitc-WT13. Smooth muscle cells were seeded at a density of $2 \times 10^{5} / 35$ mm Petri dish and incubated with DMEM supplemented with $10 \%$ FCS; $24 \mathrm{~h}$ later the medium was changed to one containing $0.4 \% \mathrm{FCS}$, and the cultures were incubated for $48 \mathrm{~h}$. At this time, the 
fluorescence-labeled analog of Fitc-WT13 was added to the cultured medium at indicated final concentrations. After $6 \mathrm{~h}$, cell fluorescence were determined by flow-cytometry analysis.

The pharmacological inhibition of Rac1 was then tested by performing a series of experiments on cultured primary human smooth muscle cells, and determining the Rac1-GTP levels by G-LISA assay. As shown in Figure 6, M1 and ST peptides significantly reduced Rac1-GTP levels at both 25 and $100 \mu \mathrm{M}$, while WT13 was inactive and Fitc-WT13 led to a partial inhibition only at $100 \mu \mathrm{M}$. The $\mathrm{IC}_{50}$ value cannot be calculated since the peptides did not reduced the Rac1-GTP levels by more than $50 \%$, but it is relevant to point out that, under the same experimental condition, the Rac 1 inhibitor NSC23766 showed, in our previous study, only an 11.1\% reduction of Rac1-GTP at $50 \mu \mathrm{M}$ concentration, while M1 and ST peptides, at the same concentration, inhibited Rac1-GTP, respectively by $30.5 \%$ and $43.3 \%{ }^{9}$ Thus suggesting that the peptides elicited a significant inhibitory effect on Rac1 with comparable potency than NSC23766.

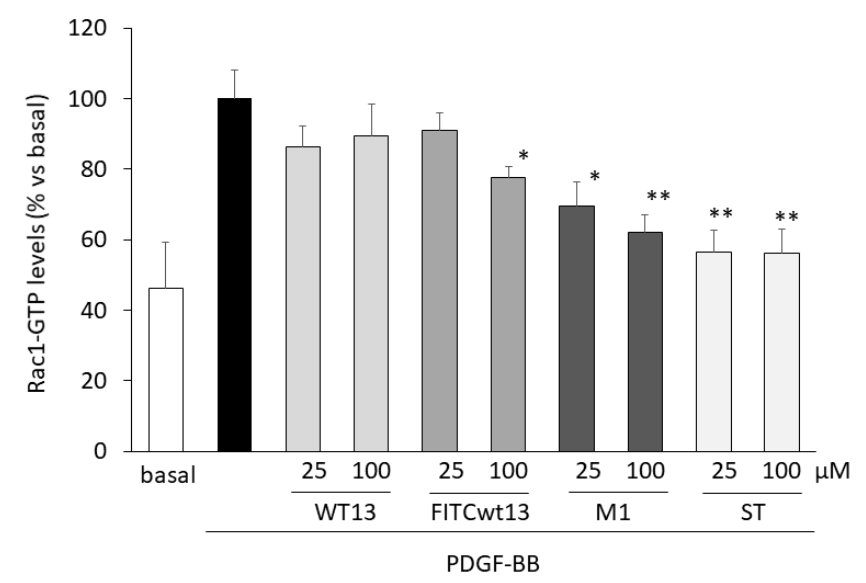

Figure 6. Effect of selected peptides on intracellular levels of Rac1-GTP levels. Smooth muscle cells were seeded at a density of $2 \times 10^{5} / 35 \mathrm{~mm}$ Petri dish and incubated with DMEM supplemented with $10 \%$ FCS; $24 \mathrm{~h}$ later the medium was changed to one containing $0.4 \%$ FCS, and the cultures were incubated for $48 \mathrm{~h}$. At this time, the peptides were added to the cultured medium at a final concentration of 25 and $100 \mu \mathrm{M}$, and after $4 \mathrm{~h}$ Rac activation was induced by PDGF-BB $(20 \mathrm{ng} / \mathrm{mL})$ for 2 min. Total protein extracts and G-LISA assays were then performed. ${ }^{*} \mathrm{p}<0.05$; ${ }^{* *} \mathrm{p}<0.01$ vs basal.

Although the actual mechanism of action of these peptides still needs to be defined, the fact that we have observed a significant inhibition of Rac1-GTP levels after the stimulation with PDGF-BB, strongly suggest their capability to interfere with the exchange between GDP and GTP. Nevertheless, 
additional experiments are required in order to define their selectivity of action towards the inhibition of PPI between Rac1 and Tiam1 or other GEFs

\section{CONCLUSION}

Starting from Rac1-Tiam1 protein-protein interface, a small library of peptides as putative PPI inhibitors has been designed. Their conformational behavior was investigated by REMD calculations and their binding energies calculated in silico using MM-GBSA approach. The introduction of an unnatural amino acid, i.e. NRB, at the N-terminus on wild type sequence was not sufficient to stabilize the helical conformation, while side-chain amide stapling increased the helix character, as confirmed by $\mathrm{CD}$ studies on synthesized peptides. The biological effect on Rac1 was investigated by the determination of Rac1-GTP levels by G-LISA assay on cultured primary human smooth muscle cells. Both the engineered peptide M1, containing NRB amino acid, and the stapled one ST significantly reduced Rac1-GTP levels at both 25 and $100 \mu \mathrm{M}$. Although we are aware that the activity of both peptides is lower than that of currently available small molecules, we think that M1 and ST might represent an interesting alternative for the development of new Rac1 inhibitors targeting Rac1-Tiam1 interface.

\section{REFERENCES}

1. Satoh, M.; Ogita, H.; Takeshita, K.; Mukai, Y.; Kwiatkowski, D. J.; Liao, J. K. Proc Natl Acad Sci U S A 2006, 103, 7432-7437.

2. Sussman, M. A.; Welch, S.; Walker, A.; Klevitsky, R.; Hewett, T. E.; Price, R. L.; Schaefer, E.; Yager, K. J Clin Invest 2000, 105, 875-886.

3. Greco, C. M.; Camera, M.; Facchinetti, L.; Brambilla, M.; Pellegrino, S.; Gelmi, M. L.; Tremoli, E.; Corsini, A.; Ferri, N. Cardiovasc Res 2012, 95, 366-374.

4. Bond, M.; Wu, Y.-J.; Sala-Newby, G. B.; Newby, A. C. Cardiovasc Res 2008, 80, 290-298.

5. Laudanna, C.; Campbell, J. J.; Butcher, E. C. Science 1996, 271, 981-983.

6. Ferri, N.; Contini, A.; Bernini, S. K.; Corsini, A. J Cardiovasc Pharmacol Cardiovasc Pharmacol. 2013, 62, 425-435.

7. Vogt, A.; Sun, J.; Qian, Y.; Hamilton, A. D.; Sebti, S. M. J Biol Chem 1997, 272, $27224-$ 27229.

8. Gao, Y.; Dickerson, J. B.; Guo, F.; Zheng, J.; Zheng, Y. Proc Natl Acad Sci 2004, 101, 76187623.

9. Ferri, N.; Corsini, A.; Bottino, P.; Clerici, F.; Contini, A. J Med Chem 2009, 52, 4087-4090. 
10. Montalvo-Ortiz, B. L.; Castillo-Pichardo, L.; Hernández, E.; Humphries-Bickley, T.; De La Mota-Peynado, A.; Cubano, L. A.; Vlaar, C. P.; Dharmawardhane, S. J Biol Chem 2012, 287, $13228-13238$.

11. Ferri, N.; Bernini, S. K.; Corsini, A.; Clerici, F.; Erba, E.; Stragliotto, S.; Contini, A.; Dharmawardhane, S.; Ferri, N. Medchemcomm 2013, 4, 537.

12. Ruffoni, A.; Ferri, N.; Bernini, S. K.; Ricci, C.; Corsini, A.; Maffucci, I.; Clerici, F.; Contini, A. J Med Chem 2014, 57, 2953-2962.

13. Cardama, G. A.; Gonzalez, N.; Ciarlantini, M.; Donadío, L. G.; Comin, M. J.; Alonso, D. F.; Menna, P. L.; Gomez, D. E. Onco Targets Ther 2014, 7, 2021-2033.

14. Cardama, G.; Comin, M.; Hornos, L.; Gonzalez, N.; Defelipe, L.; Turjanski, A.; Alonso, D.; Gomez, D.; Menna, P. Anticancer Agents Med Chem 2014, 14, 840-851.

15. Bosco, E. E.; Kumar, S.; Marchioni, F.; Biesiada, J.; Kordos, M.; Szczur, K.; Meller, J.; Seibel, W.; Mizrahi, A.; Pick, E.; Filippi, M.-D.; Zheng, Y. Chem Biol 2012, 19, 228-242.

16. Shutes, A.; Onesto, C.; Picard, V.; Leblond, B.; Schweighoffer, F.; Der, C. J. J Biol Chem 2007, 282, 35666-35678.

17. Satoh, K.; Fukumoto, Y.; Shimokawa, H. Am J Physiol - Hear Circ Physiol 2011, 301, H287H296.

18. Fosgerau, K.; Hoffmann, T. Drug Discov Today 2015, 20, 122-128.

19. Uhlig, T.; Kyprianou, T.; Martinelli, F. G.; Oppici, C. A.; Heiligers, D.; Hills, D.; Calvo, X. R.; Verhaert, P. EuPA Open Proteomics 2014, 4, 58-69.

20. Otvos, L.; Wade, J. D.; Wade, J. D. Front Chem 2014, 2, 62.

21. Dapiaggi, F.; Pieraccini, S.; Potenza, D.; Vasile, F.; Macut, H.; Pellegrino, S.; Aliverti, A.; Sironi, M.; New J Chem 2017, 41, 4308-4315.

22. Andreetto, E.; Malideli, E.; Yan, L.-M.; Kracklauer, M.; Farbiarz, K.; Tatarek-Nossol, M.; Rammes, G.; Prade, E.; Neumüller, T.; Caporale, A.; Spanopoulou, A.; Bakou, M.; Reif, B.; Kapurniotu, A. Angew Chemie Int Ed 2015, 54, 13095-13100.

23. Pellegrino, S.; Ronda, L.; Annoni, C.; Contini, A.; Erba, E.; Gelmi, M. L.; Piano, R.; Paredi, G.; Mozzarelli, A.; Bettati, S. Biochim Biophys Acta - Proteins Proteomics 2014, 1844.

24. Du, X.; Li, Y.; Xia, Y.-L.; Ai, S.-M.; Liang, J.; Sang, P.; Ji, X.-L.; Liu, S.-Q. Int J Mol Sci 2016, 17.

25. Gentilucci, L.; De Marco, R.; Cerisoli, L. Curr Pharm Des 2010, 16, 3185-3203.

26. Cativiela, C.; López, P.; Mayoral, J. Tetrahedron: Asymmetry 1990, 1, 379-388.

27. Verdine, G. L.; Hilinski, G. J. 2012; pp 3-33.

28. Kritzer, J. A. Nat Chem Biol 2016, 12, 764-765. 
29. Caporale, A.; Sturlese, M.; Gesiot, L.; Zanta, F.; Wittelsberger, A.; Cabrele, C. J Med Chem 2010, 53, 8072-8079.

30. Cunningham, A. D.; Qvit, N.; Mochly-Rosen, D. Curr Opin Struct Biol 2017, 44, 59-66.

31. Sondek, J.; Worthylake, D. K.; Rossman, K. L. Nature 2000, 408, 682-688.

32. Tarricone, C.; Xiao, B.; Justin, N.; Walker, P. A.; Rittinger, K.; Gamblin, S. J.; Smerdon, S. J. Nature 2001, 411, 215-219.

33. Molecular Operating Environment (MOE), version 2015.10 Chemical Computing Group Inc.: 1010 Sherbooke St. West, Suite No. 910, Montreal, QC, H3A 2R7, Canada), 2015.

34. Case, D.A.; Betz, R.M.; Cerutti, D.S.; Cheatham, T.E. III; Darden, T.A.; Duke, R.E.; Giese, T.J. H. G.; Goetz, A.W.; Homeyer, N.; Izadi, S.; Janowski, P.; Kaus, J.; Kovalenko, A.; Lee, T.S.; LeGrand, S.; Li, P.; Lin, C.; Luchko, T.; Luo, R.; Madej, B. ; Mermelstein, D.; Merz, K.M. ; Monard, G.; Nguyen, H.; Nguyen, H.T.; Omelyan, I.; Onufriev, A.; Roe, D.R.; Roitberg, A.; Sagui, C.; Simmerling, C.L.; Botello-Smith, W.M.; Walker, R.C. ; Wang, J.; Wolf, R.M. ; Wu, X. AMBER 2016 University of California, San Francisco 2016.

35. Jorgensen, W. L.; Chandrasekhar, J.; Madura, J. D.; Impey, R. W.; Klein, M. L. J Chem Phys 1983, 79, 926-935.

36. Hornak, V.; Abel, R.; Okur, A.; Strockbine, B.; Roitberg, A.; Simmerling, C. Proteins Struct Funct Bioinform. 2006, 65, 712-725.

37. Meagher, K. L.; Redman, L. T.; Carlson, H. A. J Comput Chem 2003, 24, 1016-1025.

38. Contini, A.; Cappelletti, G.; Cartelli, D.; Fontana, G.; Gelmi, M. L. Mol Biosyst 2012, 8, 3254.

39. Maffucci, I.; Contini, A. J Chem Theory Comput 2013, 9, 2706-2717.

40. Maffucci, I.; Contini, A. J Chem Inf Model 2016, 56, 1692-1704.

41. Miller, B. R.; McGee, T. D.; Swails, J. M.; Homeyer, N.; Gohlke, H.; Roitberg, A. E. J Chem Theory Comput 2012, 8, 3314-3321.

42. Onufriev, A.; Bashford, D.; Case, D. A. Proteins Struct Funct Bioinforma 2004, 55, 383-394. 43. Sugita, Y.; Okamoto, Y. Chem Phys Lett 1999, 314, 141-151.

44. Pellegrino, S.; Contini, A.; Clerici, F.; Gori, A.; Nava, D.; Gelmi, M. L. Chem - A Eur J 2012, $18,8705-8715$.

45. Ruffoni, A.; Contini, A.; Soave, R.; Lo Presti, L.; Esposto, I.; Maffucci, I.; Nava, D.; Pellegrino, S.; Gelmi, M. L.; Clerici, F.; George, C.; Flippen-Anderson, J. L. RSC Adv 2015, 5, 32643-32656.

46. Maffucci, I.; Pellegrino, S.; Clayden, J.; Contini, A. J Phys Chem B 2015, 119, 1350-1361.

47. Maffucci, I.; Clayden, J.; Contini, A. J Phys Chem B 2015, 119, 14003-14013. 
48. Maffucci, I.; Contini, A. J Chem Theory Comput 2016, 12, 714-727.

49. Pellegrino, S.; Tonali, N.; Erba, E.; Kaffy, J.; Taverna, M.; Contini, A.; Taylor, M.; Allsop, D.; Gelmi, M. L.; Ongeri, S.; Schmidt, M. R.; Lurz, R.; Anwyl, R.; Schnoeg, S.; Fändrich, M.; Frank, R. F.; Reif, B.; Günther, S.; Walsh, D. M.; Wanker, E. E. Chem Sci 2017, 8, 12951302.

50. Tomsett, M.; Maffucci, I.; Le Bailly, B. A. F.; Byrne, L.; Bijvoets, S. M.; Lizio, M. G.; Raftery, J.; Butts, C. P.; Webb, S. J.; Contini, A.; Clayden, J. Chem Sci 2017, 8, 3007-3018. 51. Gelmi, M. L.; Contini, A.; Bonetti, A.; Bucci, R.; Tessaro, D.; Clerici, F.; Pellegrino, S.; Nava, D. Chem - A Eur J 2017 doi: 10.1002_chem.201701045

52. Pellegrino, S.; Annoni, C.; Contini, A.; Clerici, F.; Gelmi, M. L. Amino Acids 2012, 43, 19952003.

53. Grieco, P.; Gitu, P. M.; Hruby, V. J. J Pept Res 2001, 57, 250-256. 